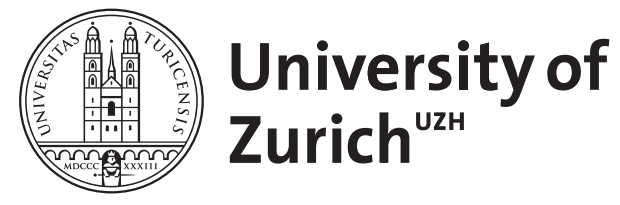

Zurich Open Repository and Archive

University of Zurich

University Library

Strickhofstrasse 39

CH-8057 Zurich

www.zora.uzh.ch

Year: 2001

\title{
Emerging roles of transporter-PDZ complexes in renal proximal tubular reabsorption
}

\author{
Biber, J
}

DOI: https://doi.org/10.1007/s004240100721

Posted at the Zurich Open Repository and Archive, University of Zurich ZORA URL: https://doi.org/10.5167/uzh-155858

Journal Article

Published Version

Originally published at:

Biber, J (2001). Emerging roles of transporter-PDZ complexes in renal proximal tubular reabsorption. Pflügers Archiv : European Journal of Physiology, 443(1):3.

DOI: https://doi.org/10.1007/s004240100721 


\section{J. Biber}

\section{Emerging roles of transporter-PDZ complexes in renal proximal tubular reabsorption}

Accepted: 21 August 2001 / Published online: 25 September 2001

(C) Springer-Verlag 2001

Keywords PDZ proteins $\cdot$ Proximal tubule

Reabsorption

In the kidneys a large part of filtered solutes is reabsorbed by specific transporters localized in the microvilli of the proximal tubular cells (PT cells). Depending on the body needs, the rates of reabsorption of certain solutes are adjusted mostly by hormonal control mechanisms. Most transporters are distributed along the whole microvilli (approx. $1 \mu \mathrm{m}$ of length) and in the case of regulated transporters, they can also be detected in the intermicrovillar clefts - the sites of internalization - associated with clathrin-coated pits/vesicles and in endosomal structures contained in the subapical compartment. From the latter, internalized transporters may recycle back to the apical membrane or may be routed to the lysosomes. This arrangement of regulated and non-regulated transporters suggests that probably all transporters interact in some way with other proteins. Such interactions are thought to be involved in: (1) the targeting of transporters to the apical membrane, (2) keeping microvillar transporters in place, (3) recruiting elements of the signalling cascades involved in regulating transport processes and (4) the processing of internalized transporters in the subapical compartment.

Very recently, we have begun to learn how supramolecular structures such as synapses are organized in terms of static and dynamic protein-protein interactions $[3,4,13]$. Proteins containing PDZ domains (name derived from the postsynaptic protein PSD95, dlg-A from Drosophila and the tight junction protein ZO-1) have emerged as important elements in organizing such membrane complexes. Several PDZ proteins have been identified that are expressed in epithelial cells and localized at the apical or the basolateral membrane. In this short commentary I shall restrict discussion to PDZ proteins

\footnotetext{
J. Biber ( E)

Institute of Physiology, University of Zurich,

Winterthurerstrasse 190, 8057 Zurich, Switzerland

e-mail: JuergBiber@access.unizh.ch

Fax: +41-1-6355715
}

localized in the brush borders of PT cells and speculate about their possible functions regarding the sorting/positioning and regulation of solute transporters.

\section{Microvillar PDZ complexes}

To date, three PDZ proteins have been described in the brush borders (microvilli and subapical compartment) of PT cells: NHERF-1 (also named EBP50) and proteins named NaPi-Cap1/2 (also known as PDKZ1, Cap70 or CLAMP).

\section{NHERF-1}

Originally NHERF-1 (encompassing two PDZ domains in tandem) was identified as a regulatory factor of the $\mathrm{Na} / \mathrm{H}$-exchanger NHE-3 and since has been established to interact with NHE-3 at or close to PDZ domain 2 [14]. In addition, evidence was obtained that NHERF-1 (via PDZ domain 1) also interacts with the $\mathrm{C}$-terminus of the $\mathrm{NaPi}$-lla protein [5] and with the adrenergic receptor $\beta 2$ [6]. Furthermore, EPI64, a protein containing a TBC/rabGAP domain implicated to play a role in vesicular membrane traffic, was recently identified to bind to the PDZ domain 1 of NHERF-1 as well [11]. Although EPI64 is abundant in kidney tissue its cellular localization remains to be determined.

On the other hand, NHERF-1 interacts with ezrin, a member of the ERM family of actin binding proteins. Ezrin itself interacts with actin filaments and additionally provides an anchoring site for protein kinase $\mathrm{A}$.

\section{$\mathrm{NaPi}-\mathrm{Cap}$ proteins}

Based on a yeast two-hybrid screen, two PDZ proteins were identified which interact with the $\mathrm{C}$-terminus of the $\mathrm{Na} / \mathrm{Pi}$-cotransporter type lla: NaPi-Cap1 and NaPi-Cap2 (85\% homologous to NaPi-Cap1) [5]. Both proteins en- 
compass four PDZ domains in tandem. Immunohistochemistry revealed that, in the kidney, these two proteins are only localized in proximal tubules: NaPi-Cap1 was predominantly observed in the microvilli, whereas NaPiCap2 was preferentially observed in the subapical region.

The interaction of NaPi-lla with the NaPi-Cap $1 / 2$ proteins was mapped to PDZ domain 3 and occurs predominantly via the last three amino acids (TRL). Other proximal tubular apically expressed proteins, MRP2 and a small, cancer-associated, protein named MAP17, were reported to interact with NaPi-Cap1 as well [8].

\section{Functional consequences of PDZ-transporter interactions}

Best described examples of regulated proximal tubular membrane transport proteins are the $\mathrm{Na} / \mathrm{H}$-exchanger NHE-3 [9] and the Na/phosphate cotransporter NaPi-lla [10]. The following roles (experimentally established and speculated) of PDZ interactions with these transporters in the brush borders of PT cells can be envisaged.

\section{Apical membrane targeting/positioning}

Roles of PDZ interactions have emerged more and more in the targeting and correct positioning of membrane proteins. In the case of the cotransporter NaPi-lla, it was shown that apical expression of the transporter in OKcells could be disturbed by truncating the last three Cterminal amino acids and thereby preventing the interaction with PDZ domain 3 of NaPi-Cap1 [7]. It has yet to be determined if this observation is due to a defect in the targeting machinery as such or a defect in the final positioning.

\section{Control of transport rates}

Both transporters, NHE-3 and NaPi-lla, are regulated by parathyroid hormone (PTH), among others. PTH inhibits these transporters in different ways: inactivation of the NHE-3 exchanger initially occurs through phosphorylation "in situ" followed by internalization [9], whereas the $\mathrm{NaPi}$-1la cotransporter undergoes immediate internalization upon PTH receptor stimulation [10]. Moreover, internalized NHE-3 transporters are recycled back from the subapical compartment to the apical membrane, whereas internalized NaPi-lla cotransporters are routed to the lysosomes. How could PDZ interactions participate in such regulatory events?

a. By anchoring components of signalling pathways? PTH stimulates PKA activity, and PKA-mediated phosphorylation inhibits NHE-3 transport activity. It has been established that the phosphorylation of NHE-3 depends on the interaction with the NHERF- 1/ezrin complex, which serves as an anchor site for PKA. Interestingly, phosphorylation (probably via a G-protein-coupled receptor kinase 6A) of NHERF-1 was demonstrated as well; however, the interaction of NHERF-1 with NHE-3 does not seem to depend on such phosphorylation and appears to be constitutive. In contrast, the interaction of NHERF-1 with the $\beta 2$ receptor appears to be more dynamic and depends on receptor stimulation [2].

It is not yet known whether the NHERF-1/ezrin/PK-A complex is necessary for regulation of the NaPi-lla transporter, or whether NaPi-Cap1 also provides anchoring sites for regulatory elements (PKA or PKC).

b. By directly interacting with transporters? Although possibly not directly relevant to the regulation of NHE-3 and NaPi-lla, studies of the interaction of CFTR with NaPi-Cap1 and NHERF-1 provide evidence for a new phenomenon of how PDZ interactions may modulate channel (transporter) activities [1]. Such activation may occur through the recruitment of regulatory subunits or the stabilization of oligomeric forms of channels or transporters. Note, however, that the presence of CFTR in the apical membrane of PT cells remains somewhat controversial.

c. By participating in the migration of transporters along the microvilli? Internalization of NaPi-lla and NHE-3 occurs in intermicrovillar clefts. How do transporters reach this site? It is currently not clear whether transporters constantly move from the clefts to the tip of microvilli and back again, and are then internalized at the clefts upon a signalling event, or if movement down to the clefts is provoked by a specific signal. In any case, both models suggest that interactions of these transporters with PDZ proteins may not be of a static nature but may exist in an "on-off" mode.

d. By sorting internalized transporters? Both transporters, NHE-3 and NaPi-lla, are internalized at intermicrovillar clefts via clathrin-coated pits/vesicles. Internalized transporters are either recycled back to the apical membrane (NHE-3) or routed to the lysosomes (NaPi-1la). This implies that NHE-3 and NaPi-lla contained in endosomal structures of the subapical compartment are handled differently. Interestingly, the PDZ domain 4 protein NaPi-Cap2 was found predominantly in the subapical compartment and was found to interact with NaPi-1la, but not with NHE-3. This suggests that NaPi-Cap2 may play a role in the sorting and routing of internalized NaPi-lla cotransporters. A possible role of NHERF-1 in the recycling of NHE-3 can be envisaged, analogous to the recycling of the $\beta 2$-receptor for which the importance of NHERF-1 has been demonstrated [12].

\section{How complex will it be?}

To date, in brush borders of PT cells, only a few membrane protein-PDZ interactions have been described (Fig. 1). Certainly there will be many more, as indicated 


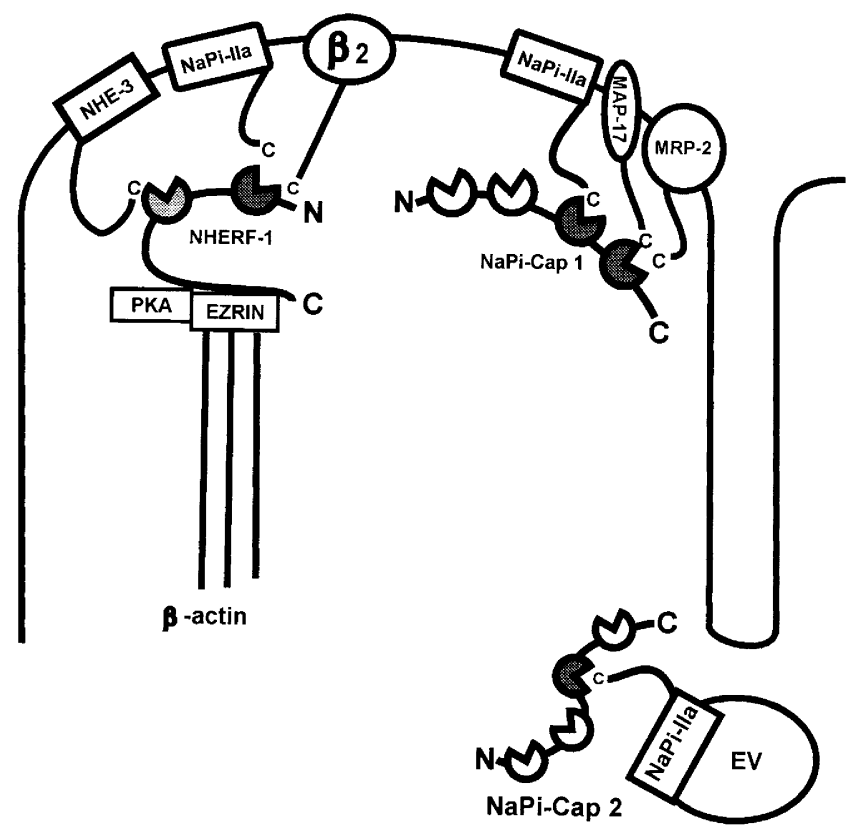

Fig. 1 Schematic arrangement of described PDZ interactions in the brush borders (microvilli and subapical compartment) of proximal tubular cells. ( $E V$ Endosomal vesicle.) Interactions that remain to be identified are indicated by a clear three-quarter circle

by the still empty sites of the NaPi-Cap $1 / 2$ proteins. Most of these interactions are via a class I PDZ binding motif (S/T-X-L) but we have to assume that interactions based on class II PDZ binding motifs $(\phi-X-\phi)$ also occur; the corresponding PDZ proteins remain to be identified.

Current results suggest that certain proteins interact exclusively with one PDZ domain while others may interact with several PDZ domains such as the NaPi-lla cotransporter, which interacts with both NHERF-1 and NaPi-Cap1. Clearly, the relative affinities of such multiple interactions remain to be determined. But importantly, these findings also raise the question about possible modulations of PDZ interactions. Controlled on-off reactions may be necessary, such as in the case of the regulation of the NaPi-lla and the NHE-3 transporter. On-off reactions may be necessary (1) to allow a controlled movement of these transporters along the microvilli or (2) to control internalization at the intermicriovillar clefts.

Taken together we shall be confronted with an orchestrated assembly of static and dynamic interactions of PDZ domains with membrane proteins (transporters, receptors) and cytosolic proteins (cytoskeletal and signalling elements) in the microvillus of PT cells. To date, most PDZ interactions have been described by in vitro approaches and by studies performed on cell cultures. It will be a formidable task to unravel the precise physiological and pathophysiological roles of the known and as yet unidentified PDZ interactions in the microvilli of PT cells using all available techniques.

Acknowledgements The author is grateful for all the experimental and theoretical help provided by Heini Murer, Nati Hernando, Serge Gisler, Sandra Pribanic and Ian Forster.

\section{Selected references}

1. Bezprozvanny I, Maximov A (2001) PDZ domains: more than just a glue. Proc Natl Acad Sci USA 98:787-789

2. Cao TT, Deacon HW, Reczek D, Bretscher A, Zastrow M (1999) A kinase-regulated PDZ-domain interaction controls endocytic sorting of the $\beta 2$-adrenergic receptor. Nature 401:286-289

3. Fanning AS, Anderson JM (1999) PDZ domains: fundamental building blocks in the organization of protein complexes at the plasma membrane. J Clin Invest 103:767-772

4. Garner CC, Nash J, Huganir RL (2000) PDZ domains in synapse assembly and signalling. Trends Cell Biol 10:274-280

5. Gisler SM, Stagljar I, Traebert M, Bacic D, Biber J, Murer H (2001) Interaction of the type IIa $\mathrm{Na} / \mathrm{P}_{\mathrm{i}}$-cotransporter with PDZ proteins. J Biol Chem 276:9206-9213

6. Hall RA, Ostedgaad LS, Premont RT, Blitzer JT, Rahman N, Welsh MJ, Lefkowitz RJ (1998) A C-terminal motif found in the $\beta 2$-adrenergic receptor, $\mathrm{P} 2 \mathrm{Y} 1$ receptor and cystic fibrosis transmembrane conductance regulator determines binding to the $\mathrm{Na} / \mathrm{H}$ exchanger regulatory factor family of PDZ proteins. Proc Natl Acad Sci USA 95:8496-8501

7. Karim-Jimenez Z, Hernando N, Biber J, Murer H (2001) Molecular determinants for apical expression of the renal type lla $\mathrm{Na} / \mathrm{Pi}$-cotransporter. Pflügers Arch (in press) DOI s004240100602

8. Kocher O, Comella N, Gilchrist A, Pal R, Tognazzi K, Brown LF, Knoll JHM (1999) PDKZ1, a novel PDZ domain containing protein up-regulated in carcinomas and mapped to chromosome 1q21, interacts with cMOAT ( MRP2), the multidrug resistance associated protein. Lab Invest 79:1161-1170

9. Moe OW (1999) Acute regulation of proximal tubule apical membrane $\mathrm{Na} / \mathrm{H}$ exchanger NHE3: role of phosphorylation, protein trafficking and regulatory factors. J Am Soc Nephrol 10:2412-2425

10. Murer H, Biber J (1997) A molecular view of proximal tubular inorganic phosphate $\left(\mathrm{P}_{\mathrm{i}}\right)$ reabsorption and of its regulation. Pflügers Arch 433:379-389

11. Reczek D, Bretscher A (2001) Identification of EPI64, a TBC/ rabGAP domain-containing microvillar protein that binds to the first PDZ domain of EBP50 and E3KARP. J Cell Biol 153:191-205

12. Shenolikar S, Weinman EJ (2001) NHERF: targeting and trafficking membrane proteins. Am J Physiol 280:F389-F395

13. Tomita S, Nicoll RA, Bredt DS (2001) PDZ protein interactions regulating glutamate receptor function and plasticity. J Cell Biol 153:F19-F23

14. Weinman E, Minkoff C, Shenolikar S (2000) Signal complex regulation of renal transport: NHERF and regulation of NHE3 by PKA. Am J Physiol 279:F393-F399 